\title{
Making sense of social pretence: The role of the dyad, sex and language ability in a large observational study of children's behaviours in a social pretend play context
}

\author{
Jenny L. Gibson ${ }^{1}$ Elian Fink $^{1,2}$ Pablo E. Torres ${ }^{3}$ Wendy V. Browne ${ }^{1}$ \& Silvana Mareva ${ }^{1}$
}

\author{
${ }^{1}$ PEDAL, Faculty of Education, University of Cambridge; \\ ${ }^{2}$ Centre for Family Research, University of Cambridge; \\ ${ }^{3}$ UCL Knowledge Lab, Institute of Education, University \\ College London
}

NB This is a pre-peer-review pre-print version of a paper currently submitted to Social Development

Acknowledgements Thanks to participating children, schools and families. Thanks to James Adams for help with preliminary literature reviewing.

Jenny Gibson and Elian Fink are funded by the LEGO Foundation.

Data Availability Statement Data have not yet been shared but the data that support the findings of this study are available from the corresponding author upon reasonable request.

\begin{abstract}
Pretend play with peers is thought to be an important driver of social development in the preschool period, however, fundamental questions regarding the features of children's social pretend play with a peer, and importantly the role of the dyad for pretend play have been overlooked. The current study undertook detailed behavioural coding of social pretend play in 134 pairs of 5-year-old children $(54 \%$ boys) in order to address three main aims: (i) describe the duration and proportion of children engaging in a number of social pretend play behaviours, namely, calls for attention, role assignment, joint proposals, and enactment of pretend play, (ii) to examine the role of the dyad in influencing the duration of different social pretend play behaviours, and (iii) assess the role of individual child characteristics (i.e., language ability and sex) that may influence social pretend play behaviours over and above the influence of the dyad. Results demonstrated the overwhelming role of the dyad in shaping children's social pretend play behaviours, with language ability and sex contributing relatively little to the total variability in play behaviours observed. Results are discussed with respect to the contribution that this type of study can make to theories of the association between children's social development and social pretend play.
\end{abstract}

Index Terms-Pretense, Play, Language Development, Sex, Observational Methods

\section{Introduction}

Pretend play has long been a subject of interest to psychologists. One approach has been to study pretence as a mechanism to address theoretical questions about the development of children's capacities in representation, meta-representation and logical reasoning (Karniol, 2016). A related stream of research asks whether and how engaging in pretend play may be related to aspects of children's development more directly; for example, by acting as a kind of 'melting pot' where the child can bring all existing competencies together to drive development in new directions (e.g., Bergen, 2013; Lillard et al., 2013; Weisberg, Hirsh-Pasek, \& Golinkoff, 2013). Despite decades of research on the topic, however, the literature on pretend play is difficult to navigate and firm, coherent conclusions about its role in social development remain elusive. Such difficulties stem from a variety of causes including differences in definitions of pretend play, methodological challenges and differing aims across studies (see review by Lillard et al., 2013).

The current study is part of a much larger empirical effort to understand the role of social pretend play with peers (for brevity, we refer to this henceforth as 'social pretend play') in children's social development. It is our contention that, despite some excellent studies in the earlier literature, the pervasive uncertainty in the field is, at least in part, due to a dearth of detailed observational research mapping exactly what children do during pretend play and how such interactions unfold over time. We agree with Lillard et al.'s (2013) proposition that controlled experimental designs may be useful to answer causal questions about the role of pretence in development, but suggest that, in the case of social pretence in particular, the field may have moved prematurely to causal hypothesis testing over systematic observation, the earlier but no less important stage of the scientific method (Pellegrini, 2001; Pellegrini, Symmons, \& Hoch, 2004). We review some of the existing observational research before outlining the aims of the current study. Our focus is on research that has investigated social pretend play between peers and excludes studies of outdoor play or studies of adult-child interactions.

Observational methods for children's social pretend play typically focus on its occurrence, frequency, features and/or 
quality, alongside assessment of child characteristics such as engagement, proclivity to play socially, or enjoyment. Within the observational research tradition, social pretend play is most commonly elicited using specific stimuli, the ensuing behaviours are video recorded and coded according to a set of criteria. The challenge for such methods is that play comprises several different behaviours and psychological stances, some of which may be directly observable, and others which must be inferred from the unfolding interaction (Berk, Mann, \& Ogan, 2006; Burghardt, 2011; Krasnor \& Pepler, 1980; Sutton-Smith \& Kelly-Byrne, 1984). Therefore, many different coding schemes for social pretend play have emerged based on researchers' differing perspectives on what play is or which features should be considered important.

A frequent distinction is the division of social pretend play episodes into play negotiation (also called play co-operation, Dunn, Cutting, \& Fisher, 2002) and play enactment. This contrasts the 'out-of-frame' behaviours, in which children negotiate the terms of the pretend play, and the play enactment (for a review, see Lillard, Pinkham, \& Smith, 2011). These two constructs, play negotiation and enactment, have been conceptualised in many different ways. Giffin (1984), for example, suggested that play ranges along a continuum from proposals and plans to actual enactment. However, the first step of engaging in social pretend play is the acknowledgement of the play partner and explicitly inviting them into a shared play space, with either verbal enticements, such as 'look here', or simply showing a play object to a partner (Garvey, 1990). This form of play behaviour is rarely examined in the play literature, and when it has, it has been coded as object offers (Werebe \& Baudonniere, 1991) or calls for attention (Farver \& Shin, 1997). Whereas, other researchers interested in the unfolding of play behaviour have shown that the negotiation phase to create a make-believe plan precedes the actual enactment of the pretence (for example Doyle, Doehring, Tessier, de Lorimier, \& Shapiro, 1992). Researchers exploring this aspect of play have considered the "joint proposals' that children make in order to agree the pretend play scenario, and the assignment of the roles that will be taken during the enactment phase (Astington \& Jenkins, 1995).

While the studies reviewed above have all contributed much to the conceptualisation and understanding of various aspects of pretend play, it is striking that the social nature of these interactions has been somewhat neglected. Given that social pretence unfolds in an interaction, play partner behaviours are likely to be an important driver of the child's behaviour during social play. Despite the clear nonindependence of data elicited from paired interactions, to the best of our knowledge, few studies has explicitly modelled the influence of partner behaviour between peers in the context of dyadic play. One very recent notable exception is the work by Etel and Slaughter (2019) who found that coordination and communication during play were highly non-independent in dyadic play (ICCs between .48 and .90). It is possible that a lack of consideration of the interaction of the dyad during play underlies the inconsistencies in the literature to date, and furthermore, failing to account for partner behaviour is likely to obstruct any attempts to characterise how child-level characteristics contribute to social pretend play behaviours (or vice-versa).

Having outlined the characteristic behaviours that have been observed in studies of social pretend play, we now turn to an examination of the association of these behaviours with child-level characteristics. Given the need to focus our efforts in this initial observational stage, we consider associations of social pretend play behaviours with linguistic ability and how these vary by sex, as both factors have been proposed as fundamental influences on social development (Rose-Krasnor, 1997).

\section{Language and social pretend play}

Close links have been observed between the development of linguistic competence and the emergence of pretend behaviours in early childhood (Garvey \& Kramer, 1989; McCune, 1995 Orr \& Geva, 2015). For the most part, investigations have focused on single word vocabulary. Positive correlations have been observed between receptive vocabulary and number of pretend play turns, as well as frequency of co-operative pretend play and social play (Dunn \& Cutting, 1999; Johnson, 1976). These observations have led researchers to conclude that both pretence and language are based on a common component of meta-representational capacity. Karniol (2016) has argued that pretence is essentially both a social and linguistic phenomenon, relying on referential intersubjectivity and pragmatic inferencing regarding the 'truth value' of utterances involving pretence. Considering peer social pretence in particular, the 'negotiation' and 'enactment' behaviours discussed above require children to use linguistic competence to understand, direct and act upon their peers' implicit or explicit mental states (Trawick-Smith, 1998). A handful of studies have looked at links between pretend play and the higher-level aspects of linguistic development that such interactions require as pretend play increases in complexity, usually focused on narrative abilities (e.g., Dunn \& Cutting, 1999; Stagnitti \& Lewis, 2015). In the current study, we build on existing research by considering sentence-level receptive and expressive language ability.

\section{Sex differences in children's pretend play behaviours}

While boys and girls tend to play in ways that reflect stereotypical masculine and feminine roles and themes (e.g., Rubin, Fein, \& Vandenberg, 1983), findings are equivocal when it comes to examining differences between boys and girls with respect to the structural components of play. For example, numerous studies have failed to find a difference in the amount of pretend play enactment between boys and girls (Dunn \& Hughes, 2001; Farver, Kim, \& Lee-Shin, 2000; Farver \& Shin, 1997; Li, Hestenes, \& Wang, 2016) or negotiation (Astington \& Jenkins, 1995), while others have found that boys (e.g., Rubin, Maioni, \& Hornung, 1976) or girls (e.g., Maguire \& Dunn, 1997) are more likely to engage in pretend play, and girls are more likely to negotiate about their play compared to boys (McLoyd, Ewart, \& Warren, 1984). Another study has shown that girls make significantly more 
conversational utterances (and therefore potentially engage in greater negotiation) during play compared to boys (Werebe \& Baudonniere, 1988).

Comparing the duration of social play to non-social play has also revealed sex differences which may shed some light on the differing role play has for boys compared to girls. In a study by Coplan and colleagues (2001) solitary-passive play was associated positively with adjustment for girls, and negatively for boys, suggesting that different aspects of play may have differential predictive links with adjustment for boys compared to girls. Together, these studies suggest that sex differences in children's play are not straightforward and require a more nuanced understanding of the components of play and the child-level characteristics that shape play interactions in addition to sex.

\section{The current study}

The current study observed social pretend play in 134 pairs of 5-year-old children playing with objects (i.e., a playmobile zoo and castle) that have been used to elicit play and social interaction in previous research (e.g., Ensor, Marks, Jacobs, \& Hughes, 2010; Kuhnert, Begeer, Fink, \& de Rosnay, 2017) in order to address three main aims: (i) to undertake a descriptive observation of the duration and proportion of children engaging in a number of social pretend play behaviours, namely, calls for attention, role assignment, joint proposals, and enactment of pretend play, (ii) to examine the role of the dyad in influencing the duration of different social pretend play behaviours, and (iii) assess the role of individual child characteristics (i.e., language ability and sex) that may influence social pretend play behaviours over and above the influence of the dyad.

\section{Methods}

\section{Ethics}

Ethical review and permissions were obtained from the Institutional ethics committee. As participants about whom the data was collected were minors, parents/caregivers gave informed written consent on their behalf.

\section{Participants}

Participants were 244 reception-aged children (131 boys, $54 \%$ ) between the ages of 49 and 78 months (Mage $=61$ months, $\mathrm{SD}=4.8$ months). The sample was recruited (with written parental consent for each child) from 14 classrooms in eight schools in the Cambridge area (UK). A total of $84 \%$ of children had at least one parent who had completed tertiary education, while $9 \%$ of children were eligible for pupil premium (additional funding for disadvantaged children of all abilities). Six children were excluded from the analysis, 4 due to developmental disorders and 2 because they were observed playing with a sibling rather than a peer. A further 9 children were away on the day of testing, resulting in a total sample of 229 (122 boys, 53\%) children in the sample.

Pairs of children were selected based on children's sex and age, such that children were paired together with a peer that was both sex-matched and age-matched as is typical in research partnering up children into play pairs for observation (e.g., Kuhnert et al., 2017; Werebe \& Baudonniere, 1988). In total, there were 134 play pairs (72 boy-boy, 62 girlgirl), however, due to the fact that some classrooms had an odd number of children or if the target playmate was absent on the days of the school-visit, and to avoid pairing children with playmates that they actively disliked (based on both child- and teacher-reports), some children were paired twice $(\mathrm{n}=39)$. All children played with a child in their classroom, and knew their playmate well. When a child played twice, only their first play experience was included in the following analyses. There was no significant difference in average age of the pairs as a function of sex, $\mathrm{t}(127)=1.17, \mathrm{p}=0.243$.

\section{Measures}

Language ability. Children's language abilities were assessed using the Clinical Evaluation of Language Fundamentals - Preschool 2 (CELF - Preschool 2, Wiig, Secord, \& Semel, 2004), a widely-used and validated measure to assess both expressive and receptive language skills. Expressive language abilities were measured using the Recalling Sentences subtest. For this task, the experimenter read aloud a sentence, and asked the child to repeat the sentence verbatim. Sentences progressed in length and grammatical complexity. Receptive language abilities were measured with the Sentence Structure subtest, which involved children picking a picture that matched a sentence read aloud to them by the experimenter. Each subtest was scored according to the CELF-Preschool 2 manual. Raw scores were used in analyses to allow the independent influence of age to be ascertained.

Observations of Social Pretend. Social pretend play was coded from a videotaped interaction of a free-play interaction between two classmates. Pairs of children were left alone with a specific toy, either a Playmobil zoo or castle in a counterbalanced order.

The mean length of coded play interactions was 7.69 minutes ( $\mathrm{SD}=59$ seconds). Inevitably, there were some periods of the play interaction that were not able to be coded (e.g., when child spoke to someone other than their playmate, had to be taken to the bathroom, etc.) or when the children were out of the frame of the video camera $(M=29$ seconds, SD $=28$ seconds of non-coded time per play interaction). In these instances, coding was paused and resumed when the child/children returned into frame.

A coding scheme was developed based on the extant literature exploring young children's social pretend play behaviours. Four observable dimensions of children's social pretend play were coded, (1) calls for attention, (2) joint proposals, (3) role assignment, (4) pretend play enactment.

Calls for Attention. This was coded when the target child made an explicit overture to their play partner to share attention. Calls for attention were coded when children showed an object or action explicitly to their play partner, and was often accompanied by verbalisations such as 'look', 
'hey', 'here', 'see?'. This code included pointing to an object with a clear intention to demonstrate something (either toy or pretend event) of interest to playmate (e.g., "Look! Put your hand in here. That is where the robber was falling."). This has been previously coded in the play literature as object offers (Werebe \& Baudonniere, 1988) and calls for attention (Jo Ann M Farver \& Shin, 1997).

Negotiation. Play negotiation was coded based on indicators previously used in the literature (Astington \& Jenkins, 1995; Jenkins \& Astington, 2000) and comprised:

Role assignment. Verbally assigning a pretend role to themselves or to another child (e.g. "You be mummy"), and had to be carried out outside of the enactment (i.e., out of character). This code included the assignment of roles through 'role phrases' that specified a proper role (e.g. "I am the person who bought this castle") and excluded assigning roles to the figurines rather than to the self or to the child's playmate (Werebe \& Baudonniere, 1991).

foint proposals. For this behaviour to be coded, children had to make reference to another person and to the self within the same turn outside of enactment of pretend play (e.g., "You have to stay in my arms", "Pretend you're squirting me again"). Reference to self and the other was inferred from the use of first-person plural pronouns such as 'we', 'us', or 'our' to specify the self and other (e.g., "Let's make cookies", "Let's go, under the umbrella in case someone squirts us", Astington \& Jenkins, 1995; Jenkins \& Astington, 2000). The code also included proposals about where things should go in the frame of the pretence (e.g. "Let's put the penguins there", "We should put these in the lions' area", Astington \& Jenkins, 1995; Doyle \& Connolly, 1989).

Pretend play enactment. Pretend play enactment was coded when a child took on the identity of someone else, speaking within the context of the pretence, or when actions, objects, persons, animals, places were transformed and animated (Doyle \& Connolly, 1989; Youngblade \& Dunn, 1995). Coding this behaviour included tone of voice (e.g., change in pitch), physical gesture (e.g., waving), stance (e.g., angry), or actions (e.g., shooting) which generally accompanied the content of the child's speech (e.g., "I am shooting a big lion" while making shooting noises). The behaviour could involve substituting a different (or similar) object for the referent (Smith, Englander, Lillard, \& Morris, 2013).

Coding for all behaviours was conducted using Observer XT (Noldus, 2008). This behavioural coding software suite allowed continuous second-by-second coding and analysis. Calls for attention, role assignment and joint proposals were converted into a frequency per minute score, while enactment was converted into a percentage duration score. Both the rate and the percentage scores were based on the codable duration of the play interaction. Each of the codes were scored focusing on a single child from the dyad at a time.

Reliability. Two coders, blind to the study hypotheses, were trained in reliability by independently scoring a random sample of 37 children (15\% of sample). Inter-rater reliability was high, Cohen's kappa for the rate of calls for attention $(=.76)$ role assignment $(=.83)$ and joint proposals $(=$
$.79)$, and duration of enactment $(=0.75)$. These reliabilities are comparable to similar observational measures in the literature (e.g., Doyle \& Connolly, 1989; Jenkins \& Astington, 2000). Discrepancies were resolved via discussion.

\section{Analysis Plan}

We first present traditional analysis examining mean levels, sex differences and associations within the play codes, as well as bivariate association across play and children's language ability. However, in order to account for the dyadic nature of the data, multilevel modelling (MLM) was used to test whether there was a direct association between children's, age, sex and their expressive and receptive language skills (predictor variables), and the behaviours observed in the play interaction (outcome variables). MLM takes into account the non-independent nature of the data and allows child-level variables to be modelled accounting for the nested structure of the data (Kenny, Kashy, \& Cook, 2006). The models were constructed with all child-level predictors as fixed effects. To support interpretation of the interaction terms, we used grand mean centering to centre the childlevel continuous predictors. A separate model was run for each outcome variable, as multivariate tests are not possible within the MLM framework.

For the current analyses, first, the baseline model (step 0) was conducted to estimate the overall dyad-level variance in play behaviours. The step allows for a test of the consistency in behaviour within pairs and demonstrates the degree to which play partners behaved similarly in the social pretend play context or if their responses were independent (Kenny et al., 2006).

Second, age, sex, expressive and receptive language were included in the model (step 1). Finally, interactions between sex and expressive/receptive language were included at the last step (step 2). At each stage, incremental model fit was estimated to assess if the additional predictors explained significantly more of the variability in play behaviours. For each model, we report the intraclass correlations that represents the amount of variance in play behaviours that is accounted for by dyad. In this way, the amount of variance explained by the independent variables in the model that was previously attributable to the dyad can be evaluated. Incremental model fit was determined by comparing log-likelihood ratios. All analyses were conducted in MPlus version 8 (Muthén \& Muthén, 2018). MLR estimation was used, which accounts for missing data, In order to compare model fit when using MLR as an estimator, a scaling correction must be applied, after which the chi-square difference (TDr) test may be used (Satorra \& Bentler, 2010).

\section{Results}

\section{Observed pretend play behaviours}

Descriptive statistics for play behaviours are presented in Table 1 . The majority of children made a call for attention to their play partner and almost all children engaged in play enactment at some point during the dyadic interaction. The two codes comprising play negotiation, role assignment and 


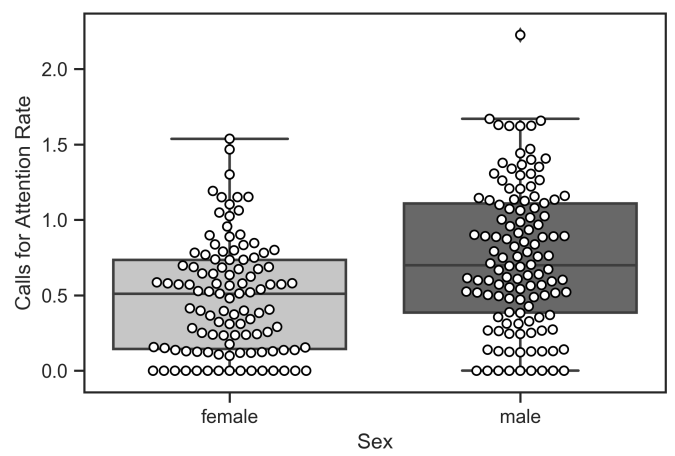

Figure 1. Distribution of observations for the Calls for Attention code (rate per minute of play) by sex.

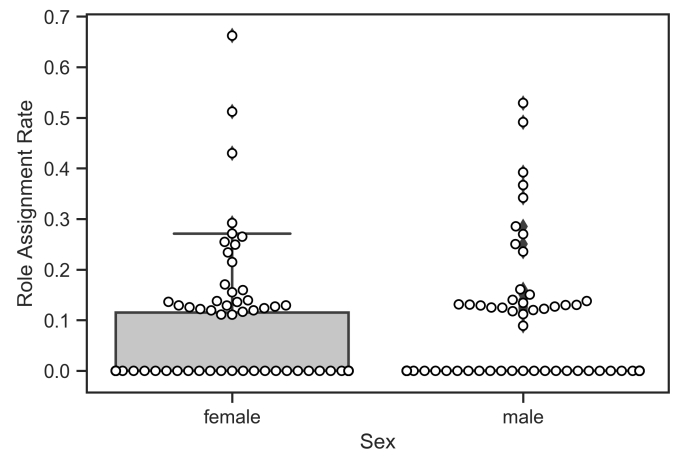

Figure 2. Distribution of observations for the Role Assignment code (rate per minute of play) by sex.

joint proposals, however, were less likely to be observed. Distributional plots of the play behaviours (separate by sex) are shown in Figures 1-4.

Given the skewed nature of this type of data (as evidenced from figs 1-4, many behaviours were not observed at all during the interaction), all scores were log-transformed to more closely approximate normal distribution and limit the range of scores. This transformation improved the distribution, and standardised transformed scores were used in all subsequent analyses.

Mean differences based on the standardised transformed scores between boys and girls were explored using independent samples t-tests (see Table 1) and showed that, while there was no difference in the frequency of role assignment and joint proposals with respect to sex, boys were more likely to make calls for attention and engage in greater enactment compared to girls. Girls had significantly higher expressive and receptive language skills compared to boys.

Bivariate associations among study variables are presented in Table 2. It should be noted that although bivariate associations are commonly reported for dyadic data and we include here to aid comparisons across different studies, given the non-independent nature of the play pairs, the findings from this type of analysis should be interpreted cautiously. In light of this, Spearman's correlations are used as recommended by Kenny, Kashy and Cook (2006). Two features of Table 2 are noteworthy. First, joint proposals

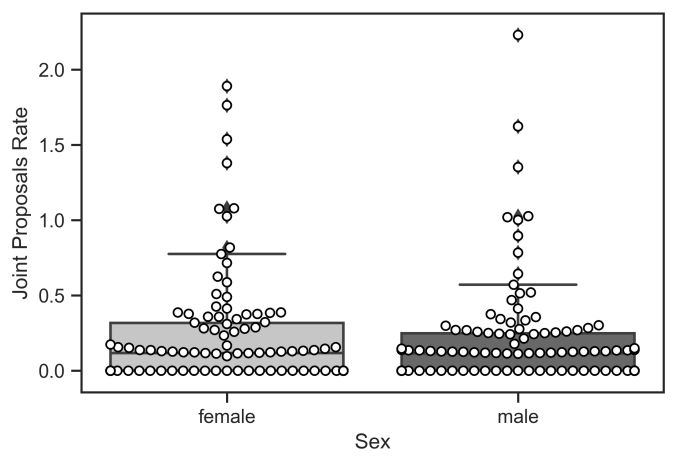

Figure 3. Distribution of observations for the Joint Proposals code (rate per minute of play) by sex

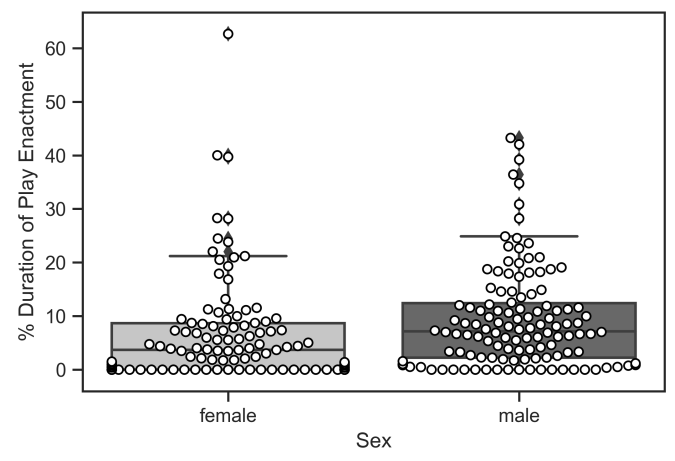

Figure 4. Distribution of duration of Play Enactment code ( $\%$ of codeable interaction) by sex.

were significantly positively associated with calls for attention and role assignment, while only role assignment was significantly positively associated with enactment. Second, expressive language, not receptive language ability, showed a specific positive association with children's play negotiations, that is joint proposals and role assignment.

\section{Role of the dyad in observed pretend play and associations with language}

MLMs to evaluate the amount of variability in play behaviours that are attributable to the dyad, in addition to the role of individual child language were conducted (see Table 3). First, for calls for attention, the baseline model indicated that $10.4 \%$ of variability in this behaviour could be explained by the dyad before the inclusion of any child-level variables. The inclusion of child-level variables significantly improved model fit, TRd $=15.28$, and explained an additional $2.1 \%$ of variance in joint attention. However, at this step, no child-level variable emerged as independently significant. The inclusion of the interaction terms at step 2 did not improve model fit, TRd $=5.70$.

For joint proposals, the baseline model indicated that $22 \%$ of the variability in joint proposals was accounted for by dyad before any child-level variables were included. In step 1 , including age, sex, and language ability improved model fit, likelihood ratio test accounting for the scaling factor for MLR: $\operatorname{TRd}(4)=13.51$, explaining an additional $1.6 \%$ of the variability 
Table I

MEANS, STANDARD DEVIATION AND RANGE OF RATE (PER MINUTE OF PLAY) OF RAW SCORES FOR CALLS FOR ATTENTION, ROLE ASSIGNMENT AND JOINT PROPOSALS, AND PERCENTAGE DURATION OF ENACTMENT ARE PRESENTED, IN ADDITION TO THE PERCENTAGE OF CHILDREN ENGAGING IN EACH BEHAVIOUR AT LEAST ONCE. COMPARISONS ACROSS BOYS AND GIRLS FOR EACH BEHAVIOUR IS ALSO PRESENTED USING TRANSFORMED SCORES.

\begin{tabular}{|c|c|c|c|c|c|c|c|}
\hline & $\mathrm{N}$ & $\begin{array}{c}\text { Mean } \\
(\mathrm{SD})\end{array}$ & Range & $\%$ & $\begin{array}{c}\text { Girls } \\
n=107\end{array}$ & $\begin{array}{c}\text { Boys } \\
n=\end{array}$ & $t$-value \\
\hline Calls for attention & 229 & $\begin{array}{c}.63 \\
(.45)\end{array}$ & $\begin{array}{c}0- \\
2.23\end{array}$ & 89.5 & $\begin{array}{l}-0.23 \\
(.85)\end{array}$ & $\begin{array}{c}0.17 \\
(1.04)\end{array}$ & $3.20 * *$ \\
\hline Role Assignment & 228 & $\begin{array}{c}.05 \\
(.11)\end{array}$ & $\begin{array}{c}0- \\
0.66\end{array}$ & 24.6 & $\begin{array}{c}0.06 \\
(1.05)\end{array}$ & $\begin{array}{c}-0.04 \\
(.96)\end{array}$ & -0.77 \\
\hline Joint Proposals & 228 & $\begin{array}{c}.20 \\
(.35)\end{array}$ & $\begin{array}{c}0- \\
2.23\end{array}$ & 52.6 & $\begin{array}{c}0.07 \\
(1.06)\end{array}$ & $\begin{array}{c}-0.05 \\
(.94)\end{array}$ & 0.28 \\
\hline Enactment & 228 & $\begin{array}{c}8.76 \\
(10.19\end{array}$ & $\begin{array}{c}0- \\
65.14\end{array}$ & 80.7 & $\begin{array}{c}-0.21 \\
(1.01)\end{array}$ & $\begin{array}{l}0.20 \\
(.95)\end{array}$ & $3.19 * *$ \\
\hline Expressive language & 228 & $\begin{array}{l}21.64 \\
(8.54)\end{array}$ & $0-37$ & - & $\begin{array}{l}0.21 \\
(.92)\end{array}$ & $\begin{array}{r}-0.17 \\
(.98)\end{array}$ & $-3.07 * *$ \\
\hline Receptive language & 228 & $\begin{array}{l}16.02 \\
(3.84\end{array}$ & $3-22$ & - & $\begin{array}{l}0.18 \\
(.89)\end{array}$ & $\begin{array}{l}-0.12 \\
(1.04)\end{array}$ & $-2.35^{*}$ \\
\hline
\end{tabular}

${ }^{*} p<.05 .{ }^{* *} p<.01$.

in joint proposals. Expressive language was a marginally significant independent predictor of joint proposals, suggesting that as expressive language increases so does the rate of joint proposals within the dyad. Including interactions between sex and language ability did not significantly improve model fit; TRd $=0.93$.

For role assignment, the baseline model indicated that $35 \%$ of the variability in role assignment was accounted for by dyad before any child-level variables were included. In step 1, including age, sex, and language ability significantly improved model fit, $\operatorname{TRd}(4)=17.13$, explaining an additional $1.1 \%$ of the variability in joint proposals. Age and expressive language were both significant independent predictors of role assignment, suggesting that as age and expressive language increase, so does the rate of role assignment within the dyad. Receptive language ability was a marginally significant predictor, and interestingly this trend indicated that as receptive language skills decreased, role assignments within the dyad were more frequent. Including interactions between sex and language ability did not significantly improve model fit; TRd $=1.18$.

Finally, examining enactment, the baseline model indicated that $43.8 \%$ of the variability in enactment is explained by the dyad. The inclusion of child-level variables at step 1 significantly improved model fit, TRd $=12.84$, and explained an additional $2.7 \%$ of variance in enactment. At this step, sex was the only significant independent predictor, such that boys were more likely to engage in this type of behaviour compared to girls. Including interactions between sex and language ability did not significantly improve model fit; TRd $=3.97$.

\section{Discussion}

The present study tells us a great deal about the nature of play behaviours that can be observed in a social pretence context. A substantial majority of children $(>89 \%)$ engaged in behaviours to gain their partner's attention, supporting the position that establishing a 'common ground' for the ensuing interaction is important groundwork for play scenarios to unfold. Similarly, and as expected, most children engaged in pretend play enactment $(80.7 \%)$. Perhaps most interestingly, based on the descriptive results concerning the play behaviours, the 'negotiation' codes - role assignment and joint proposals - were observed in just $24.6 \%$ and $52.6 \%$ of cases. This finding does not support the theoretical proposition that enticement to join in pretend play is usually present in the form of negotiations that set the scene for play enactment (Garvey, 1991). Instead, the results indicate that that there are other routes from the initiation of joint attention through to play enactment than those captured in traditional negotiation codes. 
Table II

BiVARIATE SPEARMAN CORRELATIONS BETWEEN STUDY VARIABLES

\begin{tabular}{llllrrr}
\hline & 1 & 2 & 3 & 4 & 5 & 6 \\
\hline 1. Calls for attention & - & $.22^{*}$ & .07 & -.01 & -.05 & -.04 \\
2. Joint proposals & & - & $.29 * *$ & .03 & $.13^{*}$ & .08 \\
3. Role assignment & & & - & $.16^{*}$ & $.14^{*}$ & .05 \\
4. Enactment & & & & - & -.10 & -.06 \\
5. Expressive language & & & & - & $.63^{* *}$ \\
6. Receptive language & & & & & - \\
\hline
\end{tabular}

${ }^{*} p<.05 .{ }^{* *} p<.01$.

Table III

RESULTS OF MULTILEVEL REGRESSION MODELS EXAMINING INFLUENCE OF CHILD-LEVEL FACTORS ON OBSERVED BEHAVIOURS IN THE PLAY INTERACTION.

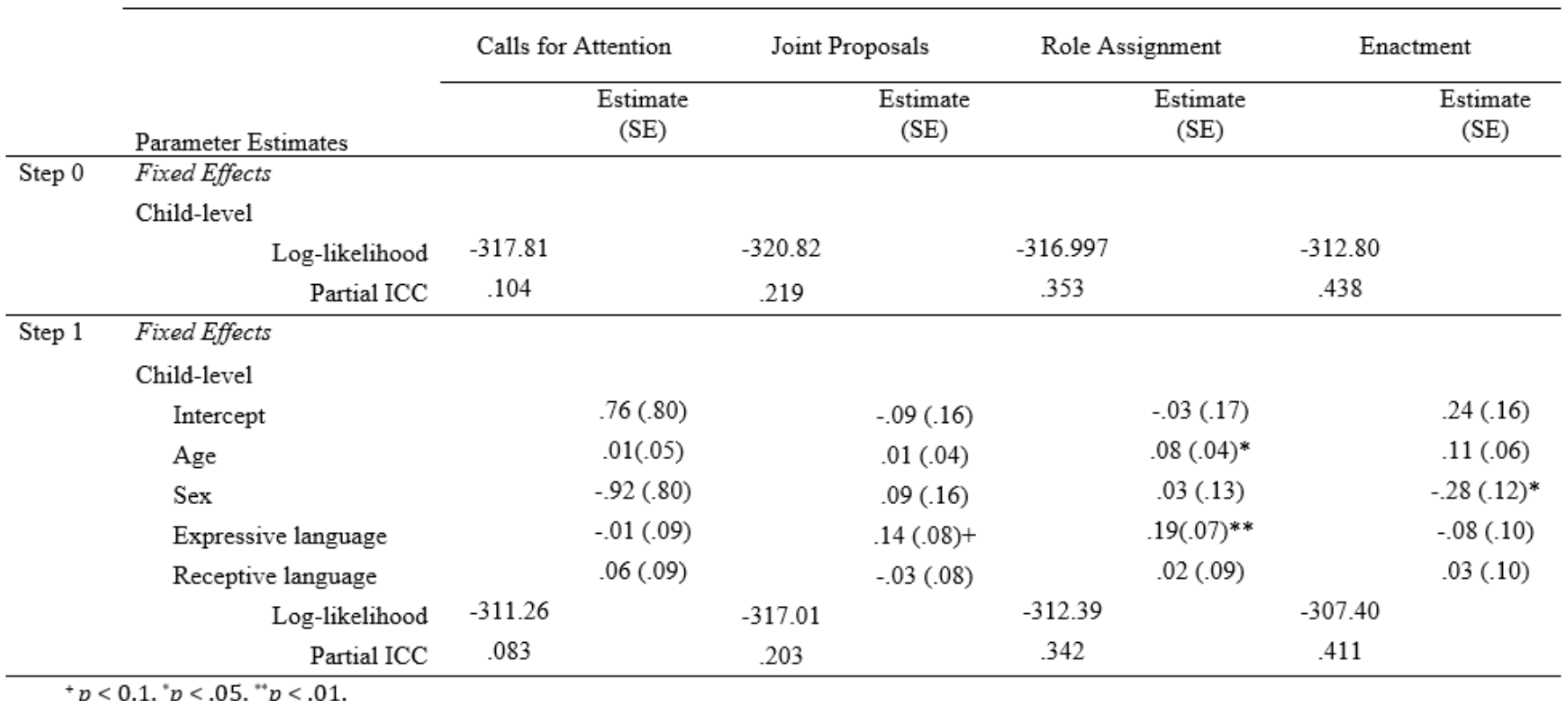

The duration of enactment episodes observed in this study $(\mathrm{M}=8.8 \%)$ is consistent with Youngblade \& Dunn's (1995) observation that around $10 \%$ of observed social pretence is characterised by enactment behaviours. Taken together, the descriptive findings indicate that there is still work to be done to capture and understand the nature of what actually happens during bouts of social pretending between peers. Future work could investigate this more closely using sequential analyses to determine the transitional probabilities for various precursors to enactment.

Turning to our second research objective, the most important finding of the present paper concerns the contribution of dyad effects in explaining variance in observed play behaviours. The partial intra-class correlations (reported in Step 0 of Table 3 above) illustrate the non-independence of all observed play behaviours. In other words, the play behaviours of a given child were influenced by the play behaviours of their play-partner. The magnitude of these effects ranged from small to moderate, and they were statistically significant (although marginally so for the "calls for attention' code). Interestingly, the dyadic effects appeared strongest ( $44 \%$ of variance explained) for 'enactment', perhaps indicating that children demonstrate higher levels of sociallycoordinated behaviour when actively engaged in social pretence. Dyadic effects were weakest for the 'calls for attention' code $(10 \%$ of variance explained), presumably because the 
nature of this play behaviour involves initiation rather than coordination with a play partner. The two 'negotiation' codes 'joint proposals' and 'role assignment' had dyadic effects of $22 \%$ and $35 \%$ respectively.

We propose that these findings inform the future of pretend play research. For those wishing to test theories relating specifically to the role of pretence in child development (Lillard et al., 2013; Weisberg et al., 2013), it is important to note the relatively short duration of pretence enactment during naturalistic play and the extent of the partner effects influence this behaviour. Future studies attempting to isolate putative effects of social pretence on development should include partner effects in statistical models. Further, there is work to be done to establish the extent of typical variance associated with partner change. In other words, it has yet to be established whether some children are more prone to partner effects on their play behaviours than others. Tentatively, we hypothesise that those children more able to adapt to their partner during pretend play will be those who are more socially skilled.

The final aim of the present study was to explore whether individual differences influence play behaviours, over and above the influence of the dyad. We focus on language ability and sex as two of the most commonly studied child characteristics when considering social pretend play.

As reported in the results section, including individual predictors in the model for 'calls for attention' significantly improved fit but no single predictor emerged as making an important individual contribution. This was by far the most frequently observed play behaviour and this finding may reflect the fact that almost all children will be skilled in bidding for a play partner's attention by the time they reach 4 years of age and therefore individual differences were marginal (especially as individuals with developmental disabilities are not included in this analysis).

For the next model, 'joint proposals', $22 \%$ of variance was explained by the dyad level, while age, sex, and linguistic ability accounted for just $1.6 \%$ of additional variance explained. At the individual level, expressive language skill was a marginally significant predictor of the variance of jointproposals. This is a novel yet intuitive finding as proposals tend to be made verbally. Similarly, expressive language was also a significant individual predictor of variance in 'role assignment' during play. This link between expressive language competence and ability to engage in play negotiation is significant given that children with low language abilities at school-entry have an elevated risk of psychosocial difficulties emerging in later childhood and adolescence, with peer relationships being a particular area of vulnerability. Such risk persists after controlling for other risk factors such as low SES and other early adversities. One hypothesis is that such children struggle to use language effectively to engage in the social learning opportunities afforded by peers (Fujiki, Brinton, \& Todd, 1996). The findings from the present study may be useful for pinpointing likely areas of challenge in engaging in social play for children with language difficulties. Further work could investigate how supportive interventions can be devised to support the development of play negotia- tion skills.

However, in contrast to previous research (e.g., Dunn \& Cutting, 1999), we did not find effects of receptive language on joint proposal rate. This is likely to be an effect of using both receptive and expressive measures that investigate sentence-level linguistic skill (rather than single word vocabulary). Possibly, previous findings based on receptive vocabulary only are due to receptive vocabulary being closely linked to overall linguistic competence (Bornstein, Hahn, \& Putnick, 2016).

Regarding sex differences, despite the sex-segregated nature of children's play interactions at this age, and the evidence suggesting that girls are more likely to engage in negotiation of play compared to boys (e.g., McLoyd, Thomas, \& Warren, 1984) when accounting for the dyad and children's language ability only frequency of enactment was different across the girl dyads compared to boy dyads. Boys were observed to engage in significantly more play 'enactment' compared to girls, which has also been observed in more naturalistic observational studies (McLoyd, Warren, \& Thomas, 1984).

\section{Moving the field forward}

Having reviewed and discussed our findings in depth, we now turn to a more general discussion of how this study contributes to our stated aim of using detailed observational research to contribute to theory development. For the purposes of understanding links between social pretence and children's social development, the present findings indicate that more attention should be paid to the interactional contexts of peer play. The relatively small role played by child-level individual differences suggests that rather than being largely a fixed characteristic or propensity of an individual, the manifestation of social play behaviours will vary according to the actors involved. Thus, we predict that future work will replicate the present results in finding more variability between dyads than between individuals within them. We suggest that our findings provide supporting evidence that failure to account for dyadic effects has been a contributing factor to the significant problems of coherence and continuity in this field.

Further, we contend that this social interactional view of social pretence is consistent with the 'play as a melting pot' idea discussed in the introductory section. That is, social pretence scenarios may provide an optimised context for rehearsal of core social skills and other competencies, especially in relation to adaptation and flexibility in social encounters. This is consistent with work investigating links between social play and adaptive social functioning in animals (e.g., Pellis \& Pellis, 2013), although of course this body of literature has not focused on pretence. The relative importance of interactional context and individual differences could be established via carefully designed studies investigating contrasts in performance between play and non-play activities, as well as contrasts between solitary play and play with peers of different levels of competence.

Our findings also highlight gaps in understanding of the constituent behaviours that comprise social play. Although 
we took a relatively fine-grained approach by separating negotiation behaviours into 'joint proposals' and 'role assignment', these codes were relatively low-frequency and it is clear that there is more work in the way of detailed observational work to be done in characterising the nature of playful engagement between peers.

Finally, although individual differences effects were small, we also propose that they are an important component of understanding play dynamics. As alluded to above, understanding individual differences maybe be particularly pertinent for supporting children who struggle with joining in with play and with adapting to a social context. Future studies should explore the role of individual differences in underpinning social cognitive and executive function skills in contributing to observed variance in social play behaviours.

\section{Limitations}

Before drawing final conclusions, we reflect on the limitations of the present study. Despite some key strengths of the current study, namely a relatively large sample of over 120 pairs of children and statistical analyses that account for the dyadic nature of the peer interactions, like all research there are some limitations that should be noted. First, the peer interaction was relatively short, and comprised of a single context only. From a practical standpoint, the context and length of the session provided structure for coding behaviours, however, arguably, do not accurately represent children's naturalistic play behaviours with peers. Relatedly, a relatively narrow set of behaviours was coded. We chose to focus on behaviours that; (a) were theoretically likely in a pretend play scenario, and (b) had been coded previously in the literature. Nonetheless, there a number of other features of children's social pretend play that were not coded, including children's amity behaviours (e.g., Dunn \& Hughes, 2001) and affect (e.g., Russ, Robins, \& Christiano, 1999). Furthermore, while the structural features of children's play were the focus of the current study, the themes of children's play are also likely to be influenced by both the dyad composition and reflect individual child characteristics (e.g., Dunn \& Hughes, 2001). Future research combining both the themes and structural aspects of children's play from a dyadic perspective would advance the literature further.

\section{Conclusions}

The current study represents an important first step in documenting children's play behaviours, and in doing so, demonstrates the key influence of the dyad composition for understanding what children do when they play with their peers. When compared to the dyad composition, the influence of child characteristics such as age, sex and language were exceedingly small. Future research examining the temporal sequence of how different observed play behaviours unfold within the dyad will shed further light on how these behaviours are manifest in play and has the potential to inform strategies to support those children who may be struggling to maintain peer interactions.

\section{REFERENCES}

Astington, J. W., \& Jenkins, J. M. (1995). Theory of mind development and social understanding. Cognition and Emotion, 9(2-3), 151-165. doi:10.1080/02699939508409006

Bergen, D. (2013). Does pretend play matter? Searching for evidence: comment on Lillard et al.(2013). Psychological Bulletin, 139(1),

Berk, L. E., Mann, T. D., \& Ogan, A. T. (2006). Makebelieve play: Wellspring for development of self-regulation. In D. G. Singer, R. M. Golinkoff, \& K. Hirsh-Pasek (Eds.), Play= learning: How play motivates and enhances children's cognitive and social-emotional growth (pp. 74-100). Oxford: Oxford University Press.

Bornstein, M. H., Hahn, C. S., \& Putnick, D. L. (2016). Long-term stability of core language skill in children with contrasting language skills. Developmental Psychology, 52, 704-716. 10.1037/dev0000111

Burghardt, G. M. (2011). Defining and recognizing play. In P. Nathan \& A. D. Pellegrini (Eds.), Oxford Handbook of the Development of Play (pp. 9-18). doi:10.1093/oxfordhb/9780195393002.013.0002

Coplan, R. J., Gavinski-Molina, M. H., Lagacé-Séguin, D. G., \& Wichmann, C. (2001). When girls versus boys play alone: Nonsocial play and adjustment in kindergarten. Developmental Psychology, 37(4), 464-474. doi:10.1037/0012-1649.37.4.464

Doyle, A.-B., \& Connolly, J. (1989). Negotiation and enactment in social pretend play: Relations to social acceptance and social cognition. Early Childhood Research Quarterly, 4(3), 289-302. doi:http://dx.doi.org/10.1016/0885-2006(89)90015-X

Doyle, A. B., Doehring, P., Tessier, O., de Lorimier, S., \& Shapiro, S. (1992). Transitions in children's play: A sequential analysis of states preceding and following social pretense. Developmental Psychology, 28(1), 137.

Dunn, J., \& Cutting, A. L. (1999). Understanding others, and individual differences in friendship interactions in young children. Social Development, 8(2), 201-219.

Dunn, J., Cutting, A. L., \& Fisher, N. (2002). Old friends, new friends: Predictors of children's perspective on their friends at school. Child Development, 73(2), 621-635.

Dunn, J., \& Hughes, C. (2001). "I got some swords and you're dead!": Violent fantasy, antisocial behavior, friendship, and moral sensibility in young children. Child Development, 72(2), 491-505.

Ensor, R., Marks, A., Jacobs, L., \& Hughes, C. (2010). Trajectories of antisocial behaviour towards siblings predict antisocial behaviour towards peers. Journal of Child Psychology and Psychiatry, 51(11), 1208-1216.

Etel, E., \& Slaughter, V. (2019). Theory of mind and peer cooperation in two play contexts. Fournal of Applied Developmental Psychology, 60, 87-95. doi: 10.1016/j.appdev.2018.11.004

Farver, J. A. M., Kim, Y. K., \& Lee-Shin, Y. (2000). Within Cultural Differences:Examining Individual Differences in Korean American and European American Preschoolers' Social Pretend Play. Journal of Cross-Cultural Psychology, 31(5), 583602. doi:10.1177/0022022100031005003

Farver, J. A. M., \& Shin, Y. L. (1997). Social pretend play in Korean-and Anglo-American preschoolers. Child Development, 68(3), 544-556. 
Fujiki, M., Brinton, B., \& Todd, C. M. (1996). Social skills of children with specific language impairment. Language, Speech, and Hearing Services in Schools, 27(3), 195-202.

Garvey, C. (1990). Play (Vol. 27). Cambridge, MA: Harvard University Press. Garvey, C., \& Kramer, T. L. (1989). The language of social pretend play. Developmental Review, 9(4), 364-382.

Giffin, H. (1984). The coordination of meaning in the creation of a shared make-believe reality. In I. Bretherton (Ed.), Symbolic Play (pp. 73-100). San Diego, CA: Academic Press.

Jenkins, J. M., \& Astington, J. W. (2000). Theory of Mind and Social Behavior: Causal Models Tested in a Longitudinal Study. Merrill-Palmer Quarterly, 46(2), 203-220. doi: $10.2307 / 23093714$

Johnson, J. E. (1976). Relations of divergent thinking and intelligence test scores with social and nonsocial makebelieve play of preschool children. ETS Research Bulletin Series, 1976(1), i-16.

Karniol, R. (2016). A language-based, three-stage, socialinteractional model of social pretend play: Acquiring pretend as an epistemic operator, pretending that, and pretending with (the P-PT-PW model). Developmental Review, 41, 1-37.

Kenny, D. A., Kashy, D. A., \& Cook, W. L. (2006). Dyadic data analysis: Guilford press.

Krasnor, L. R., \& Pepler, D. J. (1980). The study of children's play: Some suggested future directions. New Directions for Child and Adolescent Development, 1980(9), 85-95. doi:10.1002/cd.23219800908

Kuhnert, R., Begeer, S., Fink, E., \& de Rosnay, M. (2017). Gender-differentiated effects of theory of mind, emotion understanding, and social preference on prosocial behavior development: A longitudinal study. fournal of Experimental Child Psychology, 154, 13-27.

Li, J., Hestenes, L. L., \& Wang, Y. C. (2016). Links Between Preschool Children's Social Skills and Observed Pretend Play in Outdoor Childcare Environments. Early Childhood Education fournal, 44(1), 61-68. doi:10.1007/s10643-014-0673-2

Lillard, A. S., Lerner, M. D., Hopkins, E. J., Dore, R. A., Smith, E. D., \& Palmquist, C. M. (2013). The impact of pretend play on children's development: A review of the evidence. Psychological Bulletin, 139(1), 1-34.

Lillard, A. S., Pinkham, A. M., \& Smith, E. (2011). Pretend play and cognitive development. The Wiley-Blackwell handbook of childhood cognitive development, 285-311.

Lindsey, E. W., \& Colwell, M. J. (2013). Pretend and physical play: Links to preschoolers' affective social competence. Merrill-Palmer Quarterly, 59(3), 330-360.

Maguire, M. C., \& Dunn, J. (1997). Friendships in early childhood, and social understanding. International fournal of Behavioral Development, 21(4), 669-686.

McCune, L. (1995). A normative study of representational play in the transition to language. Developmental Psychology, 31(2), 198-206. doi:10.1037/0012-1649.31.2.198

McLoyd, V. C., Ewart, A. C. T., \& Warren, D. (1984). The Short-Term Dynamics of Social Organization in Preschool Triads. Child Development, 55(3), 1051-1070. doi: $10.2307 / 1130157$
McLoyd, V. C., Thomas, E. A., \& Warren, D. (1984). The short-term dynamics of social organization in preschool triads. Child Development, 1051-1070.

McLoyd, V. C., Warren, D., \& Thomas, E. A. (1984). Anticipatory and fantastic role enactment in preschool triads. Developmental Psychology, 20(5), 807-814. doi:10.1037/00121649.20.5.807

Muthén, L. K., \& Muthén, B. O. (2018). Mplus. Los Angeles, CA: Muthén \& Muthén.

Noldus. (2008). The observer: Professional system for collection, analysis, presentation and management of observational data (Version 8.1). Wageningen, Netherlands: Noldus.

Orr, E., \& Geva, R. (2015). Symbolic play and language development. Infant Behavior and Development, 38, 147-161.

Pellis, S., \& Pellis, V. (2013). The playful brain: venturing to the limits of neuroscience: Oneworld Publications.

Rose-Krasnor, L. (1997). The nature of social competence: A theoretical review. Social Development, 6(1), 111-135.

Rubin, K. H., Fein, G. G., \& Vandenberg, B. (1983). Play. Handbook of child psychology, 4, 693-774.

Rubin, K. H., Maioni, T. L., \& Hornung, M. (1976). Free play behaviors in middle-and lower-class preschoolers: Parten and Piaget revisited. Child Development, 414-419.

Russ, S. W., Robins, A. L., \& Christiano, B. A. (1999). Pretend Play: Longitudinal Prediction of Creativity and Affect in Fantasy in Children. Creativity Research fournal, 12(2), 129139. doi:10.1207/s15326934crj1202_5

Sachs, J. (1980). The role of adult-child play in language development. New Directions for Child and Adolescent Development, 1980(9), 33-48.

Satorra, A., \& Bentler, P. M. (2010). Ensuring positiveness of the scaled difference chi-square test statistic. Psychometrika, 75(2), 243-248.

Smith, E. D., Englander, Z. A., Lillard, A. S., \& Morris, J. P. (2013). Cortical mechanisms of pretense observation. Social Neuroscience, 8(4), 356-368.

Stagnitti, K., \& Lewis, F. M. (2015). Quality of pre-school children's pretend play and subsequent development of semantic organization and narrative re-telling skills. International journal of Speech-Language Pathology, 17(2), 148-158.

Sutton-Smith, B., \& Kelly-Byrne, D. (1984). The idealization of play. In P. K. Smith (Ed.), Play in animals and humans (pp. 305-321). Oxford: Basil Blackwell.

Weisberg, D. S., Hirsh-Pasek, K., \& Golinkoff, R. M. (2013). Embracing complexity: rethinking the relation between play and learning: comment on Lillard et al. (2013). Psychological Bulletin, 139(1), 35 - 39.

Werebe, M. G., \& Baudonniere, P.-M. (1991). Social pretend play among friends and familiar preschoolers. International Journal of Behavioral Development, 14(4), 411-428.

Werebe, M. J. G., \& Baudonniere, P. M. (1988). Friendship among preschool children. International fournal of Behavioral Development, 11(3), 291-304.

Wiig, E. H., Secord, W. A., \& Semel, E. (2004). Clinical evaluation of language fundamentals - Preschool, second edition (CELF Preschool-2). Toronto: The Psychological Corporation/A Harcourt Assessment Company. 
Youngblade, L. M., \& Dunn, J. (1995). Individual Differences in Young Children's Pretend Play with Mother and Sibling: Links to Relationships and Understanding of Other People's Feelings and Beliefs. Child Development, 66(5), 1472-1492. doi:10.2307/1131658 